\title{
EDITORIAL
}

\section{The publishing game: reflections of an editorial team}

\author{
James M Crawford ${ }^{1}$, Catherine M Ketcham ${ }^{1}$, Raul Braylan ${ }^{1}$, Laurence Morel ${ }^{1}$, Naohiro Terada ${ }^{1}$, \\ Jerrold R Turner ${ }^{2}$ and Anthony $T$ Yachnis $^{1}$
}

The close of a 5-year editorship gives opportunity to reflect on the highs and the lows of an editorship. The goal of such reflection is to assist both authors and reviewers in interacting with a biomedical journal, and to foster interest among individuals contemplating an editorship. Among the highs was the privilege of publishing high-quality original scientific work within the scope of the journal; in this instance mechanistic studies of disease. Although review articles and editorials have their reward, it is the publication of original peer-reviewed work that constitutes the true basis for advancing biomedical science. This is the heart of journal publication. Second, the editorial interaction with submitting authors in bringing their work to publication is itself highly rewarding, and can lead to longer-term collegial working relationships between editors and authors. The anonymous expert reviewers also play a key role in bringing outstanding scientific work to successful publication. Collectively, authors, editors, and reviewers constitute an important 'community of science'. Third, working together as an editorial team, especially through the weekly 'journal clubs' that a regular editorial meeting affords, is commended as a key reward of any editorial group taking on journal management. The lows included sifting through submitted manuscripts in which the rigor of science was not satisfactory, and encountering specific instances of compromised scientific integrity-fortunately rare. In both instances, the editorial commitment is to publish high-quality original science; a necessary corollary is identifying those submissions, through rigorous but fair review, which do not meet journal standards. In the end, editorship is a highly rewarding experience, and very much conducive to sustaining the wonder of science that drew us to this profession.

Laboratory Investigation (2008) 88, 1258-1263; doi:10.1038/labinvest.2008.113

${ }^{1}$ Department of Pathology, Immunology and Laboratory Medicine, University of Florida College of Medicine, Gainesville, FL, USA and ${ }^{2}$ Department of Pathology, University of Chicago Pritzker School of Medicine, Chicago, IL, USA.

Correspondence should be addressed to: jcrawford1@nshs.edu $\mathrm{n}$ March 2003, this editorial team came into being for a 5-year editorship, targeting publication of Laboratory Investigation in January 2004 as our inaugural issue, and ending with this month's issue, December 2008. At the time of our editorial coalescence, Evan R Ketcham, the 6-year-old son of our managing editor (CMK), put down on paper his thoughts about what his mother would be doing in her new editorial job with this journal. The cover of this issue takes elements from his original drawing, for the purposes of the cover format. The full drawing is given in Figure 1. We have treasured this rendering. Deep in our hearts, what biomedical scientist has not wondered about the relationship of rockits, electristy, and scklutins (sic) to her/his own particular area of research? Now a middle-schooler, Evan is kind enough to let us publish his ponderings as the cover image of this, our closing issue.

The editorial team was organized on the principles given in Table 1. The foremost goal was to publish a scientific journal of the highest quality, focused on advances in mechanistic understanding of disease. Publication of original, peer-reviewed articles was the priority. Added features of the journal were inclusion of full-length technical reports, a provocative series of 'Pathobiology-in-Focus' critical reviews, and fulllength editorial features. In the last instance, attention was given to issues within the field of academic pathology, and the 'bibliometrics' of the 


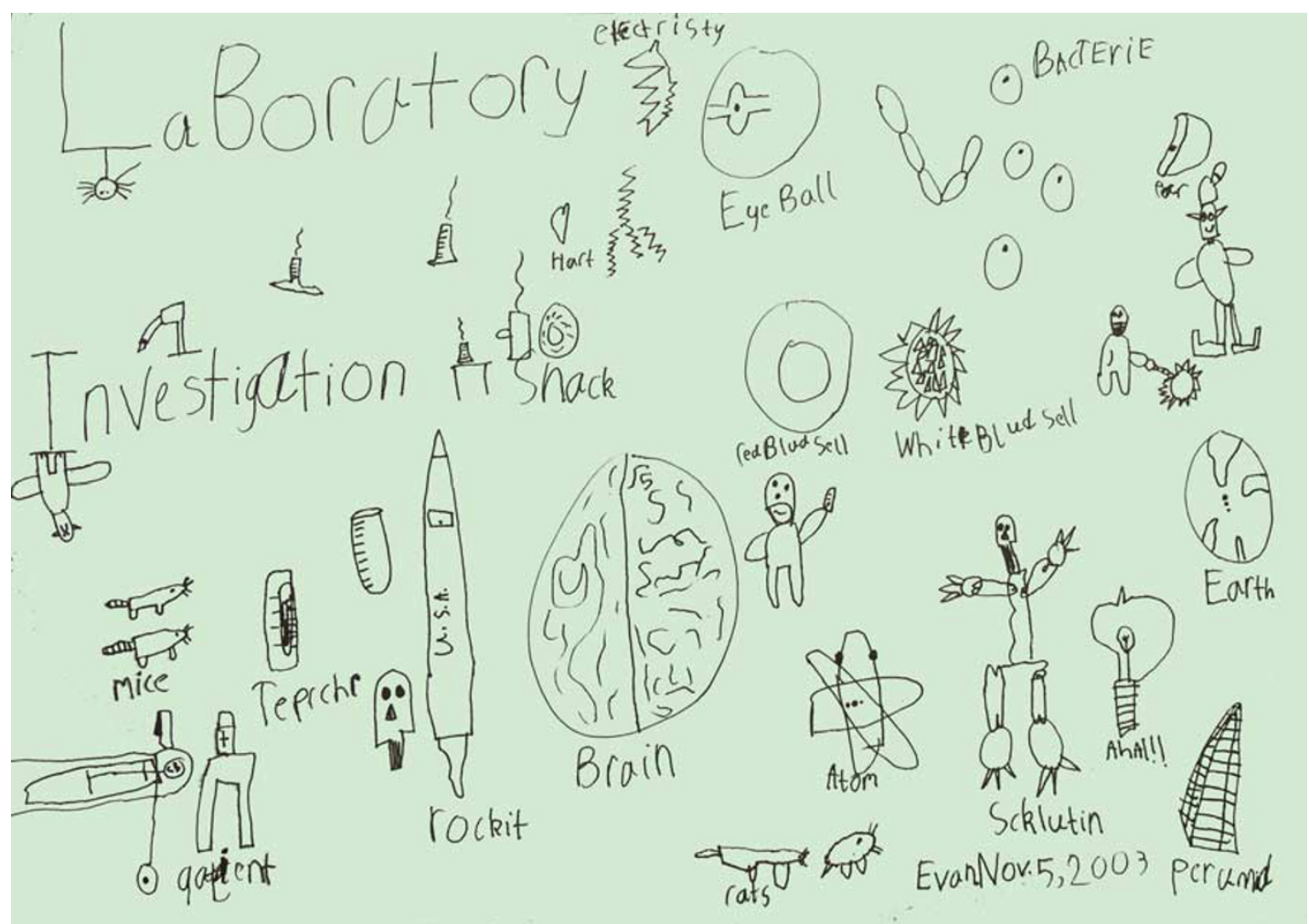

Figure 1 The job of an editor. Thoughts of Evan R Ketcham, age 6 years, upon his mother's appointment as managing editor of Laboratory Investigation, November 2003. Courtesy of Evan R Ketcham (now age 12 years).

Table 1 Organizing principles of laboratory Investigation editorship, 2004-2008 ${ }^{\text {a }}$

Publish a scientific journal of the highest quality

Focus: mechanistic understanding of human disease

Scope: original experimental studies of human disease and animal models of human disease

To include: morphologic, molecular, and in vitro studies; full-length technical reports

Features: Pathobiology-in-Focus; Inside Lab Invest; Editorial Perspectives

Operational priority: service to submitting authors

Rigorous, impartial, and fair review of manuscripts

Timely decision-making

Timely publication of accepted papers

Service to academic pathology

a Published volumes 84-88.

pathology literature. This closing editorial is our opportunity to reflect on two of the most rewarding aspects of our editorship: our interactions with authors and reviewers; and our interactions with each other.

Table 1 gives as an operational priority of this journal, support of submitting authors. In 2003, it was our perception that a key to the future success of this journal was setting a precedent for the highest quality of service in this area. Accordingly, and through the 5 years of our editorship, the full editorial team was expected to attend to incoming articles within hours of submission. Very importantly, each paper assigned to an associate editor (including the editor-in-chief and the senior associate editors acting in this capacity) was to be read and critiqued, with the goal of having all papers discussed at our weekly face-to-face editorial meeting (with one off-site senior associate editor faithfully dialing in). In this fashion, we were able to maintain consistency in adhering to the 'scope' of the journal and to the scientific standards we chose to set. For those papers we triaged (about $58 \%$ of submissions), the associate editor was expected to include in recommendations for the decision letter, explanation of why the paper fell short of journal standards. Often, these explanations amounted to a full review of the manuscript, which would be included as an attachment. In this fashion, submitting authors received what we hoped would be useful critique, even if they were subjected to editorial rejection. 
Papers advanced to full scientific review had a major advantage over those submitted to journals that did not perform editorial triage. For Laboratory Investigation, each reviewer could expect a paper already of significant quality, and hence could look forward to a more rewarding 'review experience'. Using the electronic platform of this journal, we could often measure in minutes the time it took for requested reviewers to agree to examine one of our submitted manuscripts! The ultimate acceptance rate of manuscripts subjected to full scientific review exceeded 50\%. Ofttimes, the dual reviews were extensive and daunting. Nevertheless, authors given the opportunity to respond to the reviewers' comments and resubmit a revised manuscript had a 93\% chance of acceptance for publication!

The last part of this effort was the clock, which was always running. Every member of the editorial team-managing editor, senior associate editors, and associate editors - was expected to visit upon their 'queue' at least once a day, if not several times a day-regardless of day of the week, holiday, or where they were in the world. If, heaven forbid, an editor was not going to be available, cross-coverage was arranged so that manuscripts would not be held up. The editor-inchief, and senior associate editors (who could make independent editorial decisions) carried ultimate responsibility for processing manuscripts to conclusion. Our efforts were not in vain. The average time from submission-to-final decision during our 5-year editorship was 11 days, and we did not fatigue over the course of 5 years (despite outside predictions to the contrary). Decisions on triaged manuscripts were within hours to 7 days (even after-the-fact, triaged papers were discussed at our weekly editorial meeting and, hence, 'inhouse' peer review). Ninety five percent of decisions on manuscripts submitted to full scientific review were within 5-35 days. In the latter case, our outside expert reviewers provided great assistance, as their reviews were almost always returned within 21 days, and often in less than 10 days.

Key rewards of this editorial philosophy included the development of sustained working relationships with specific authors, potentially leading to publication of a series of their articles over a 5-year period. An example was our privilege in publishing the peer-reviewed magnum opus of one scientist, Dr Bogdan Czerniak, in the July 2008 issue of this journal. ${ }^{1}$ The submitted manuscript was 130 text pages, before consideration of tables, figures, references, and appendices. The published manuscript was 28 journal pages, which with the accompanying editorial perspective, constituted $1 / 3$ of that issue's content! For this editor-in-chief (JMC), publication of this manuscript was the most rewarding editorial experience in over 15 years of editorial work. That being said, every published manuscript was a reward, not only to submitting authors, but to the editorial team. Our hope was that we could help the authors achieve excellence in their final published work. It was then very easy for the editors then to write editorial 'shorts' on selected papers, for our 'Inside Lab Invest' feature.

The rewards also came with sustained interactions with reviewers: those on the editorial board of the journal, and a worldwide galaxy of other reviewers who became friends of this journal. Many of these reviewers, selected on the basis of their individual expertise regardless of medical specialty or scientific discipline, ultimately submitted manuscripts of their own to this journal.

It is these interactions with a 'scientific public' that provide true fulfillment for an editorial team, for it is their work we publish. Put differently, the goal of an editorship is not to decide which manuscripts to reject, but to select those manuscripts that need to be published to advance biomedical science. In the process of manuscript review (both 'in-house' and with outside reviewers), editorial decision-making and advising of authors, and crafting of the final product (at that point, with particular attention to English usage and the quality of figures), the authors and editors work as a team to produce a high-quality published work.

What surprised us over the course of 5 years was the pleasure of working with one another. Taking on editorship of a major biomedical journal requires suspension of sanity, since a minimum of 6 additional hours per week (for an associate editor) to 12 to $15 \mathrm{~h}$ (for senior associate editors and the editor-in-chief) were required to run this journal-without decrement in usual responsibilities to employer and institution. The capstone of this commitment was a weekly 2-h editorial meeting (first thing Tuesday morning), in which all submitted manuscripts were discussed, whether triaged or advanced to full review. Given the scientific breadth of this journal, each week amounted to an extended 'journal club'. Beyond the extraordinary excitement of discussing the world's literature before its publication, our own 
expertise grew. The editor-in-chief (JMC) brought this editorial model to the University of Florida, having been the beneficiary of this editorial model both as a 'remote' associate editor for the University of California San Francisco-based editorial team of Hepatology (headed by D Montgomery Bissell, 1995-2000) and as an 'in-house' associate editor of Laboratory Investigation during its Yale years (Jordan Pober and Jon Morrow, editors-in-chief 1996-2003). Our University of Florida-based editorial team can emphatically echo the declaration of Paul A Marks, editor-in-chief of the Journal of Clinical Investigation (1967-1971). He states, 'It was particularly rewarding to work with the editorial board in what amounted to weekly scientific minisymposiums.' Having now moth-balled these Tuesday morning sessions, and turning the journal over to the next editorial team (led by Gene Siegal, 2009-2013), each of us admits to some withdrawal symptoms - despite regaining the time on our schedules.

These reflections can be summarized in our joint recollections of 5 years of being editors. First, what were the outcomes of manuscripts submitted to this journal? At the risk of being facetious, Figure 2 provides graphical depiction of the probable outcome of a submitted manuscript. There are several take-home points. First, we consider it worthwhile that authors attempt to publish their manuscripts. Although this statement may seem self-evident, the fact that our 'acceptance rate' remained consistently in the 22-24\% range throughout our editorship suggests that we remained true to the standards we set both for journal scope and quality, and that we were rather tough on submitting authors. However, should an author submit a manuscript both of high quality and appropriate to the journal, we felt that the manuscript would, indeed get published in this journal. Second, the number of papers accepted 'as is' (without revision) was $2.5 \%$, including invited Pathobiology-in-Focus features. Only four original experimental manuscripts were accorded this privilege over 5 years! Essentially all accepted original manuscripts required revision before acceptance. If the manuscript was 'looks OK, but needs some work', then additional experimental work was not likely to be required. The greater number of manuscripts were 'interesting idea, needs a lot of work'. In other words, additional experimental work was required. We are grateful to the many, many authors who responded to these critiques, and did, indeed, perform the additional experiments. The lesson is clear: publishing a manuscript almost always requires an extended interaction with outside (and unknown) reviewers and, yes, the journal's editors.

Second, many manuscripts were triaged simply because they fell outside the scope of the journal. This is not a negative critique of the manuscript. Instead, it is a service both to the submitting authors and to our reading public, since a journal that strays off-course does good for neither authors nor readers.

Third, it is true that many manuscripts simply did not meet journal standards for scientific quality. Our editorial opinions may seem unkind, as rendered in Figure 2. But it is

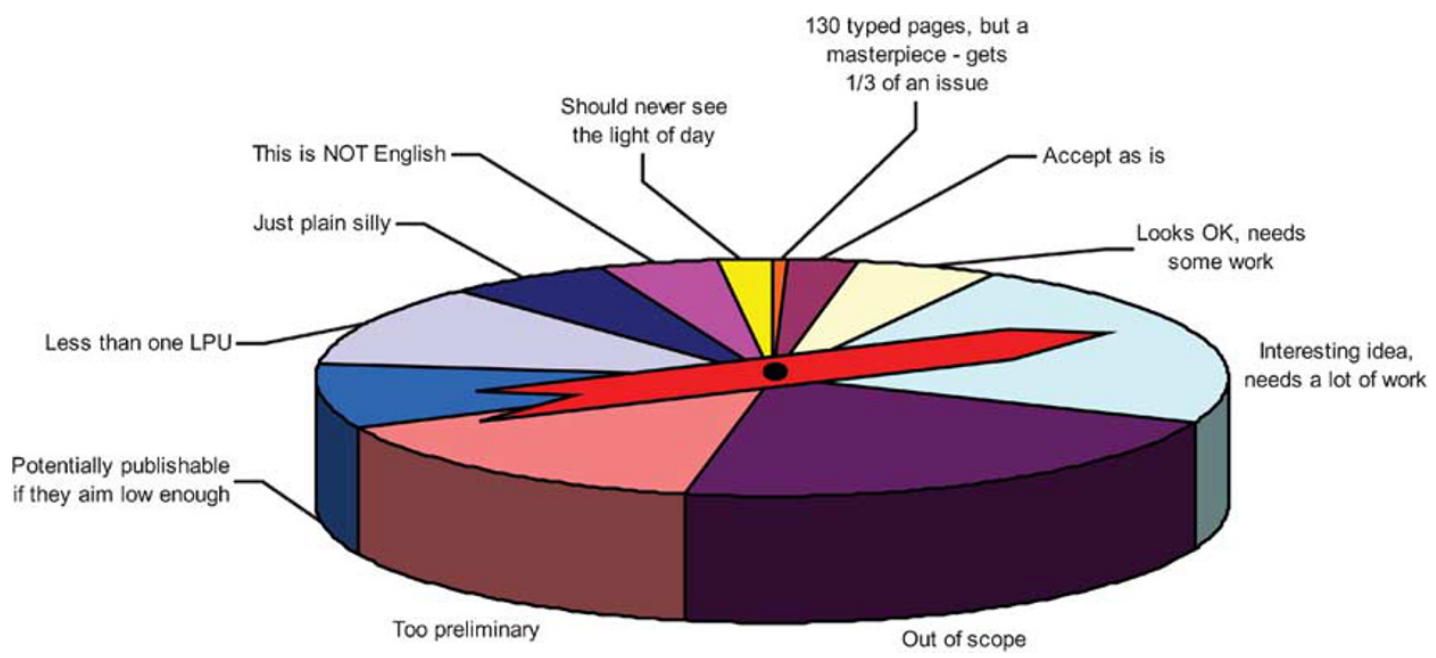

Figure 2 Editorial decision-making. Frequencies of editorial decisions, 2003-2008. The approximate reasons for an editorial decision are as given; with some editorial license in summarizing the essence of the decision. LPU: least-publishable unit. 
Table 2 Issues of scientific integrity, encountered with submitted manuscripts ${ }^{a}$

Plagiarism: two instances; in one a reviewer found that he himself had been plagiarized.

Copyright violation due to duplicate figure publication: Laboratory Investigation was just barely the first to publish the figure.

Data falsification: a submitted figure from a previously published paper had been resized, rotated $90^{\circ}$, and labeled differently within the figure.

Questionable care of animals: several papers contained studies involving questionable care and use of animals, and were not considered further.

Conflict of Interest: there were some instances of reviewers who did not reveal conflict of interest that could be construed to have either positive or negative bias, such as recent collaboration with the authors, or previous negative review of the submitted manuscript.

${ }^{\mathrm{a}}$ Total instances of questionable integrity were about 10 , out of over 2500 manuscripts reviewed over 5 years $(\sim 0.4 \%)$.

precisely the exercise of scientific judgment that is the greatest responsibility of scientific editors.

We would be remiss to overlook the downside of our editorial experience. We had personal experience with a number of ethical issues with submitted manuscripts, as given in Table 2. Flagrant instances of plagiarism, falsification of data, and dual submission were encountered. Fortunately, they were rare. We were able to identify several of these 'in-house', thanks to the mandated rigorous editorial review. Several others were identified by our expert reviewers. Remedies were taken. For the two instances of obvious plagiarism, the plagiarized author was so notified (in one instance, a former mentor). For the one instance of falsification of data (specifically, reproduction of a figure which had been resized, rotated $90^{\circ}$, and labeled differently within the figure), a stern reprimand was sent to the author. Since the paper was not published, we did not feel that notification of the author's institution was our purview. For dual submission, the editor-inchief of the other journal in which identical data were published was notified. Thanks to our rapid turnaround time on decisions, in the two instances in which this occurred, the paper had been published first in Lab Invest-but the issue remains. None of these editorial 'catches' was a rewarding experience-it is instead a sad situation. It is our earnest hope that we caught all instances of ethical breaches, and were not unwitting parties to other instances of compromised scientific ethic.
Table 3 Rewards of editorship, as recalled by the 2004-2008 editorial team of Laboratory Investigation

\begin{tabular}{|c|c|}
\hline Camaraderie & $\begin{array}{l}\text { Working and learning together; weekly } \\
\text { editorial meetings }\end{array}$ \\
\hline Teamwork & $\begin{array}{l}\text { Commitment to fair but efficient review } \\
\text { of all submitted manuscripts }\end{array}$ \\
\hline Authors & $\begin{array}{l}\text { Working relationships with correspond- } \\
\text { ing authors }\end{array}$ \\
\hline Reviewers & $\begin{array}{l}\text { Working with a cheerful, cooperative, } \\
\text { fair, honest, and thorough group of } \\
\text { diverse experts in biomedical sciences }\end{array}$ \\
\hline Editorial board & $\begin{array}{l}\text { Cultivating a selective, highly engaged } \\
\text { group of experts }\end{array}$ \\
\hline Parent Society & $\begin{array}{l}\text { Serving the broader pathology com- } \\
\text { munity through the society }\end{array}$ \\
\hline Publisher & $\begin{array}{l}\text { Working with an extraordinarily com- } \\
\text { mitted group of corporate editors and } \\
\text { staff }\end{array}$ \\
\hline Personal growth & $\begin{array}{l}\text { Opportunities across a wide-ranging } \\
\text { scientific landscape }\end{array}$ \\
\hline
\end{tabular}

But we should not end on a down note. Table 3 gives our editorial team's recollections of the rewards. In addition to those already noted earlier in the narrative, starting with interactions with authors and reviewers, several additional rewards are worth noting. Serving the parent society (the United States and Canadian Academy of Pathology; USCAP), and working with the publisher (Nature Publishing Group, NPG) are high reward indeed. In the first instance, bringing to the published literature those articles that represent the best in mechanistic pathobiology helps advance the mission of this major society. In turn, USCAP can serve as a world leader in the promulgation of new knowledge about human disease. In the second instance, we had the privilege of working with one of the world's leading publishing houses, and benefiting from their extraordinary expertise in scientific publishing. We also thank the hard-working production editors at NPG, as they brought to final publication the high-quality journal issues to which we became accustomed. More often than we would care to admit, this was against very tight publication deadlines (including the one for this editorial!).

What lessons can be taken from this editorial? First, in the midst of extraordinary changes in publishing practices and funding of biomedical research, the fundamental activity of manuscript submission and review remains an important domain of a journal. Authors should take heart that the editorial machinations of a journal have integrity and logic, and that it is worth the effort 
to respond to critiques by reviewers. Second, the community of science is well served by individuals serving as reviewers and, yes, editors. Third, an editorship is exceedingly rewarding, and is an extraordinary opportunity to serve one's peers. Lastly, serving a scientific journal helps sustain the wonder that is science: whether in the eyes of a 6-year old, or someone 9-10 times older!
Thank you for the opportunity to serve as your editors.

1. Majewski T, Lee $\mathrm{S}$, Jeong J, et al. Understanding the development of human bladder cancer by using a wholeorgan genomic mapping strategy. Lab Invest 2008:88:694-721.

2. Insel PA, Kornfeld S, Majerus PW, et al. Blasts from the past. J Clin Invest 2004;114:1017-1033. 